Revised: M ay 5, 2010

\title{
REDEFINING AND CONTAINING SYSTEMIC RISK
}

\author{
Edward J. Kane
}

Boston College

\begin{abstract}
Official definitions of systemic risk leave out the role of government officials in generating it. Policymakers' support of creative forms of risk-taking and their proclivity for absorbing losses in crisis situations encourage opportunistic firms to foster and exploit incentive conflicts within the supervisory sector. To restore faith in the diligence, competence, and integrity of officials responsible for managing the financial safety net, reforms need to rework incentives in the government and financial sectors. The goal should be to align the incentives of private risk managers, accountants, credit-rating firms, and government supervisors with those of ordinary taxpayers. This article describes a series of complementary ways of advancing toward this goal. The most important steps would be to measure regulatory performance in terms of its effect on the loss exposures that the safety net passes through to taxpayers and to require institutions that benefit from the net to produce information that would support this effort. This entails estimating the explicit and implicit safety-net benefits individual institutions receive and issuing extended-liability securities whose prices would improve the accuracy of these estimates.
\end{abstract}

*For criticism of an earlier draft, which was presented at the Inaugural Institute for New Economic Thinking at King's College, the author wishes to thank Richard Aspinwall, Stephen Buser, Charles Calomiris, Robert Dickler, Rex DuPont, Richard Herring, Stephen Kane, Allan Meltzer, Ken Scott, James Thomson, and Larry Wall. 
Government officials everywhere acknowledge a responsibility for overseeing systemic risk. But before one can begin to control a target variable (even something as straightforward as the temperature of a room), one must define the variable comprehensively and fashion from this definition one or more verifiable metrics for monitoring the target. Official definitions of systemic risk fail both of these tests.

Official definitions focus on a perceived potential for substantial spillovers of institutional defaults across important firms in the financial sector and from this sector to the real economy. These definitions are not comprehensive because they exclude a systemic phenomenon: that substantial spillovers of actual defaults have remained largely and predictably hypothetical.

Actual spillovers are minimal because authorities instinctively choose to intervene in the default process by characterizing firms that are politically or administratively difficult to fail and unwind (DFU) as "systemically important " (SI) and supporting DFU firms' credit when they allow themselves to become economically insolvent. In effect, authorities exercise a lossshifting "taxpayer put" that allows insolvent DFU firms to operate as corporate zombies (K ane, 1986; Eberlein and M adan,2010).

Official definitions of systemic risk lead to an incomplete diagnosis of its roots: that systemic risk is caused by defective risk management at DFU firms. The diagnosis is incomplete because it ignores the role of opportunism at DFU firms in exploiting gaps and incentive conflicts in policy making and it undermines accountability for regulatory mistakes because it lacks a verifiable metric. The incomplete diagnosis supports an incomplete treatment plan, one that would: toughen capital requirements; reconfigure the boundaries of regulation; and extend new powers to regulators (e.g., over executive compensation, derivatives trading, and insolvency 
resolution) without addressing the fundamental incentive conflicts that persuade authorities to undersupervise innovative forms of risk taking at DFU firms and their "shadow" banking competitors and affiliates.

Economic policymaking is a balancing act, but one in which blame avoidance distorts the release and analysis of key information. It is no accident that the official diagnosis of the securitization bubble and the treatment plan it supports do not address the endogenous role that safety-net subsidies play in incentivizing firms to operate outside the boundaries of the regulatory system and to take political and economic action to attain and strengthen DFU status. A uthorities do not wish to acknowledge that principled efforts to define and pursue the public interest are contested and repeatedly knocked off course by conflicting personal, bureaucratic, and political concerns that impinge inappropriately on government decisionmakers.

To understand why defects in insolvency detection and resolution persist, analysts must acknowledge that large financial institutions invest in disguising their risk-taking and in building and exercising political clout. M ainstream models of safety-net management are just beginning to acknowledge that, even in good times, politically powerful financial firms shape and reshape their lobbying activity, product lines, accounting systems, and organizational forms to collect hard-to-document subsidies to leveraged risk-taking from national safety nets ( $K$ ane, 2009; A charya, Schnabl, and Suarez, 2010; Eberlein and M adan, 2010).

Leveraged risk-taking intensifies financial bubbles and increases the costs to taxpayers of repairing the damage that a bursting bubble entails. To minimize the extent and frequency of future bubbles and crises, reformers must understand that safety-net subsidies trace to the political clout, managerial opportunism, and organizational flexibility that aggressive firms exercise and not to a firm's size or complexity per se. Rulemaking that adjusts accounting 
standards or sets caps on size and complexity of selected categories of firms without introducing controls on clout, opportunism, or structural flexibility strongly incentivizes efforts to deconstruct and circumvent the changes introduced.

This paper argues that, microeconomically and macroeconomically, the capitalized value of the safety-net subsidies that financial firms capture represents a cogent way to measure what authorities ought to mean by "systemic risk" and that regulation-induced innovation is the vehicle through which subsidies to systemic risk-taking are conveyed. This hypothesis implies that proposals for financial reform need to be judged by two criteria: (1) how much they promise to discourage financial institutions from abusing safety-net support and (2) how much they promise to improve the ways in which authorities measure, monitor, and restrain the flow of $\underline{\mathrm{ex}}$ ante and ex post subsidies to creative forms of institutional risk-taking.

Both within and across countries, financial systems can be made more stable by making market signals more informative. This can be done by reconfiguring the way that financial institution managers report to actual and potential regulators and the way that regulators conceive of their responsibilities to taxpayers. R eformers would do well to refocus their efforts on incentives. In government arenas, this means rewriting regulatory officials' oaths of office; changing the ways officials are recruited, trained and compensated; and reworking the ways they measure and report regulatory performance. For the private sector, this means changing the character of the debt and equity securities that important financial institutions have to issue and requiring such firms to estimate and report the putative value of the safety-net benefits they receive and to file, negotiate, and update regularly a windup plan with their chartering authority and principal regulator. 


\section{When Do Risks Become Systemic?}

Systemic risk may be likened to a disease. In medicine, comprehensive and verifiable definitions of disease lead to more accurate tests for its existence and more effective patterns of treatment. The primary characteristic of systemic risk is the emergence of widespread concerns about the potential for substantial "spillovers" of contagious defaults across counterparties in the financial sector and from these defaults to breakdowns in the real economy. This potential is traced either to individual firms' overexposure to common risk factors (underdiversification) or to a nexus of derivative contracts that result in an unobservable web of debt that highly leveraged institutions owe to one another (contagion).

These concerns cannot be the only symptom because, with the notable exception of the Lehman bankruptcy, in modern crises substantial spillovers of actual defaults have remained largely hypothetical. In country after country and sector after sector, monetary and fiscal authorities instinctively choose to intervene in the default process by supporting the credit of "systemically important" institutions that allow themselves to become economically insolvent. Such institutions are called "zombies" because the black magic of subsidized government loans and guarantees prevents their creditors from pulling the plug on their dangerous and unnaturally animated corporate corpse (K ane, 1989).

The existence of this verifiable additional symptom suggests that an authentic definition of systemic risk ought to focus on a firm's or sector's ability to command or extract implicit and explicit life support from national safety nets. Eberlein and M adan (2010) portray zombies as being allowed to exercise what they term a "taxpayer put." Highlighting this symptom links 
systemic risk not only to a condition of widespread financial weakness, but al so to unhealthy forms of competition for regulatory clients (i.e., turf) and to other factors that make a firm or collection of firms politically or administratively "difficult to fail and unwind" (DFU). Diagnosing these links makes it clear that, to be truly reliable, programs for reforming the regulation and supervision of DFU firms cannot ignore political and administrative issues. Systemic taxpayer loss exposures come not just from creative and aggressive risk-taking by DFU firms, but from defects in micro and macro prudential supervision of the leverage and other risk exposures regulated and unregulated firms take on. This layering of blame makes it clear that meaningful reform must identify and remedy the incentive conflicts that tempted authorities to ignore the buildup of systemic risk in the shadow banking system during the securitization bubble and then led them to rush to aid zombie firms when the bubble burst without developing a program to confront and resolve the zombies' growing economic insolvency in a definitive way.

\section{A dverse Consequences of M isdiagnosing the Policy Problem}

Both in medicine and in crisis management, superficial diagnoses lead to ineffective treatment and deepening infirmity. Credit spreads faced by short-funded financial institutions surged in A ugust 2007 and stayed high for months afterward. This surge lowered the value of these firms' risky assets and thereby reduced their capacity to replace their maturing debts. For months, Federal Reserve officials refused to concede that higher credit spreads had pushed asset and collateral values down to levels that raised legitimate doubts about short-funded borrowers' solvency and that these doubts underlay the collateral calls stressed by Gorton (2008) that made it difficult for highly levered firms to roll over asset-backed debt. Without acknowledging the subsidy entailed in lending to insolvent institutions or how such lending turned monetary policy 
into tax-transfer policy, Federal Reserve officials repeatedly misframed the funding difficulties that DFU firms were experiencing as evidence of a shortfall in aggregate liquidity. Financing the deepening insolvency of zombie firms such as B ear Stearns, Lehman, and A IG allowed their managers not only to pay themselves undeserved bonuses, but to gamble improvidently for resurrection at taxpayer and creditor expense.

Despite being challenged by the persistence of funding difficulties and especially by the costs of the B ear Stearns rescue in M arch 2008, remnants of the liquidity-shortage hypothesis survived until mid-September 2008. B ack-to-back policy decisions at that time consoled investors by effectively nationalizing creditor loss exposures at Fannie and Freddie, but surprised everyone by forcing creditors of Lehman to accept haircuts dictated by the bankruptcy process, and days later turned around and surprised them again by refusing to haircut the creditors and swap counterparties of the far more deeply insolvent AIG. The failure to offer a convincing rationale for shifting to and fro between contradictory insolvency-resolution strategies and resulting volatility in the value of DFU firms' "taxpayer puts" raised doubts about the diligence, integrity, and competence of Fed and Treasury officials. Consumer and investor concerns about regulatory diligence and competence were reinforced by a series of doomsday pronouncements about the size extent of industry weakness that deepened the recession by frightening the populace into cutting back their spending ( $K$ ane, 2009a).

The policy of explicitly supporting the creditors and counterparties of AIG and other zombie firms represented a new and seemingly desperate treatment plan. Its antiegalitarian effects on the distribution of income (which accorded top priority to bankers and other derivatives counterparties) were as obvious as they were hard to defend. Public justifications 
have mutated over time, but all have relied on the untestable (and insufficiently supported) claim that extravagant support of financial sector was a price that society had to pay to avoid another Great Depression.

III. A Iternative D efinitions of Systemic Risk Lead to Different Strategies of R egulatory Reform

Blame avoidance plays an unspoken role in any policy debate. B lame avoidance helps to explain why officials adopt definitions of systemic risk that lead to the self-serving hypothesis that systemic risk is caused by defective risk management at "systemically important firms" (SIFIs). U sing our definition of systemic risk, SIFIs are private firms that have made themselves politically, economically, and administratively difficult to fail and unwind. By ignoring the process by which a firm attains and solidifies DFU status, the official diagnosis of safety-net risk exposure is distressingly shallow and leads to the incomplete treatment plan of trying to identify DFU firms by size and/or business plan and demanding that such firms monitor and support their risk exposures more effectively.

In the US and Europe, the components of this incomplete plan are evolving along four principal dimensions:

1. Designing tougher and more comprehensive capital requirements for bank and nonbank financial firms (e.g., by measuring risk exposures in ever more granular ways);

2. Restricting the level and composition of executive compensation at financial firms (e.g., by limiting bonuses and incentive-based compensation at SIFIs); 
3. Enhancing the powers that government regulators may exercise (e.g., with respect to taking over or liquidating a failing institution and intervening in how and where derivatives may trade);

4. Extending the boundaries of government regulation (e.g., to encompass hedge funds, derivatives trading, and credit-rating firms).

A financial crisis occurs when a sufficient amount of adversity hits a fragile system whose managers have concentrated and leveraged their portfolio enough to make their firms vulnerable to this amount and type of adversity. Our broader definition of systemic risk recognizes that regulatory enterprises are vulnerable SIFIs, too. Their managers determine how much of the deep downside of the risk exposures that DFU institutions pursue are transferred to taxpayers. Including regulators in the risk-generation process requires us to think about how political, bureaucratic, and administrative concerns are likely to influence the way in which new controls would be deployed under various circumstances.

The buildup of systemic risk in structured securitizations was generated by short-cutting and outsourcing due diligence in both the private and government sectors. U ntil the securitization bubble burst in 2008, authorities failed to isolate and respond to the safety-net consequences of the risk transfers that were taking place al ong the chain of originating, valuing, selling, pooling, risk-rating, and insuring loans so that their risky cash flows could be engineered into highly rated tradable securities. The durability of this neglect should warn us that, to reduce the depth and frequency of future crises, it is not enough to improve the mechanics of risk control. A parallel effort must be made to reframe the incentives of the system's operators. They must be encouraged to treat the interests of ordinary citizens less callously than they have in recent years. 
Forward-looking policymakers must expect managers of financial firms to continue to mask leverage, credit, and interest-rate risk and to stall and subvert sensible reforms in order to protect their capacity to extract safety-net subsidies. To lessen their capacity to do this, officials and private managers must be tasked with estimating and controlling the effects that safety-net subsidies have on the stock price, credit spreads, and credit default swaps of the firms they oversee. The next two sections of the paper identify a few ways in which this might be done.

IV. Why Incentive Defects Persist

Blame accrues to people who do "bad" (i.e., immoral, negligent, or incompetent) things. This means that assigning blame for government and market failures that led to the securitization crisis is both an economic and an ethical problem. Ethics seep into our definition of systemic risk to the extent that industry and government officials knowingly tolerate defective institutional arrangements $^{1}$ or fail to fulfill fiduciary duties that in principle they owe to one or more participants in the securitization process.

To be complete, reform strategies must address features of top officials' employment situation that encourage weakness in insolvency detection and dispose them to subsidize the financial sector massively in times of crisis. Table 1 lists six such features. Top officials are exposed to scapegoating and the reputational risk that scapegoating entails renders more tentative their ability to stay in office. Limited terms and relatively low salaries encourage top regulators to use their government service to nurture post-government career opportunities in the very

\footnotetext{
${ }^{1}$ I have in mind the push to adopt Basel II in the face of defects such as those uncovered by Kupiec (2009).
} 
industries they regulate. It is hard for an agency's leadership to balance: (1)the certain and immediate damage to their reputations that industry criticism is bound to visit on them if and when they resist strong lobbying pressure against (2)the less certain damage their reputations might or might not suffer from public-interested censure later. In most crises, it is not until long after an official has left office that careful investigations by Inspector Generals or other watchdogs can surface irrefutable and convincing evidence about the inappropriateness of safetynet policies. In any case, once insolvencies become deep and widespread, authorities are tempted to gamble that cycle-driven improvements in industry conditions will make insolvent institutions whole again (K ane, 1989).

Their situation is further complicated by the existence of multiple principals and differences in the ability of different principals to defend their interests. Principals differ: in their understanding of the duties officials owe them, in their ex ante ability to influence official decisions in their favor, in their ability to appreciate the consequences of these decisions, and in their ex post ability to offer rewards for favorable and unfavorable decisions. The result is that de facto accountability to informed and politically powerful sectors routinely trumps the abstract duties that top regulators owe to society as a whole.

Changes in compensation structure, performance measurement, and reporting responsibilities can be designed to lessen these incentive conflicts ( $K$ ane, 2010). But the current generation of politicians and other persons in authority is unlikely to benefit from pushing for such changes. A s in a long-running poker game in which one player (here, the taxpayer) is a perennial and relatively clueless loser, other players see little reason to disturb the equilibrium. 
V. Steps that Government and Industry Could Take Toward Genuine Reform ${ }^{2}$

The essential problem of financial reform is how to incentivize safety-net managers and managers of protected institutions to serve more conscientiously the interests of the average taxpayer. To make this possible, financial firms and their supervisors must agree to work together to design, implement, and staff an information system that can measure the flow of safety-net costs and benefits and a control system that can restrain the process of subsidy generation within and across major countries.

J oint P rivate-Sector and Governmental Reforms

DFU institutions could simplify the task of safety-net management by making taxpayer stakes in these firms both more transparent and administratively easier to protect in times of duress.

One way to do this is to agree to separate the supervisory function of diagnosing systemic risk from that of treating it. Because the emergence of widespread insolvency inevitably embarrasses an agency's leaders, supervisory agencies have repeatedly succumbed to the temptation to understate or cover up surges in insolvency when they first occur. Insolvency detection can be improved by developing explicit metrics for measuring the value of safety-net support at individual institutions and requiring safety-net beneficiaries to use these metrics to estimate the value of their safety-net support and to report their estimates at regular intervals to their principal supervisor. For these estimates to be taken seriously, they must be challenged and

\footnotetext{
${ }^{2}$ This section draws heavily on Kane(2010).
} 
vetted for accuracy at each supervisory agency by competent and conscientious risk-management personnel.

Individual-institution data must then be aggregated across firms and across supervisory agencies. To minimize incentive conflicts that arise in staffing this function and in processing politically sensitive information, the task of aggregating and publicizing the estimates should be assigned to a new federal entity (Levine, 2009; Lo, 2009) or to a special division of the Government A ccountability office specifically charged with measuring and monitoring safetynet costs and benefits. The idea is to not only to separate accountability for mismonitoring safety-net subsidies from accountability for underpolicing them. It is also to make someone specifically responsible for identifying on an ongoing basis the ways in which regulation-induced innovation might be exploiting loopholes in the current structure of regulatory authority.

M onitoring Systemic Risk. The layering of blame for the current crisis implies that private and government sources of systemic risk must be monitored and policed jointly. A lthough still at an early stage, econometric strategies for measuring safety-net subsidies al ready exist. Following the lead of M erton $(1977,1978)$, researchers have developed several promising metrics that a Safety-N et A ccountability Office (SAF) could use to assess the value of safety-net support from balance-sheet and market data. Ronn and V erma (1986), Duan, M oreau, and Sealey(1992), Hovakimian and K ane (2000), and Carbo, K ane, and Rodriguez (2009) estimate the value of safety-net support from data on a banking organization's stock price. These models show that the value of safety-net credit support increases dramatically as it stockholdercontributed capital begins to disappear. B aker and M cA rthur (2009) extract estimates from a firm's credit spread. Hart and Zingales (2009) show the usefulness of data on the prices of 
institutions' credit default swaps. Huang, Zhou, and Zhu (2009) use stock price, credit spreads, and credit default swap data simultaneously. Finally, Eberlein and M adan (2010) combine data on equity option prices with balance sheet data on the same dates to calculate values for the taxpayer put. At yearend 2008, they estimate loosely that, for six of the most important US SIFIS, safety-net subsidies totaled over 860 billion dollars, with individual benefits ranging from a low of $\$ 3.37$ billion (at Goldman Sachs) to $\$ 293.96$ billion (at J PM organ Chase).

Of course, the capitalized value of taxpayer costs for supporting safety-net benefits is generally less than the sum of the benefits that accrue to individual firms. But because correlations increase in crises and asset bubbles, it may not be much less. The costs of supporting the safety net may be analyzed as the return from a portfolio of the imperfectly correlated positions in the various firms the net protects. Research on correlations shows that the effects of crisis-generating and other large common industry shocks are more highly correlated than smaller common shocks that industry capital is expected to absorb(see, e.g., Gropp and M oerman, 2003).

To establish a better framework for analysis, I propose to divide responsibilities for collecting and processing dataon safety-net benefits into at least three pieces. The first segment would task managers of financial firms with estimating and reporting to their primary regulators (on, say, a quarterly basis) interval estimates of the value of the safety-net benefits their firm receives. Especially for large or complicated firms, this task could (as discussed later) be streamlined by requiring financial institutions to issue securities that automatically convert to equity in troubled circumstances or carry extended liability. The second segment would task individual regulators with examining (i.e., conscientiously challenging the accuracy of) these 
estimates and undertaking correlation studies that would allow them to prepare interval estimates of the aggregate value of taxpayer support accruing to the firms they supervise. The third segment would task the regulators to report and justify their estimates and aggregation procedures to the Safety N et A ccountability Office and task the SAF with publically reporting interval estimates of the aggregate value of safety-net subsidies for different industry sectors. A fourth segment could eventually task SA Fs in different nations with establishing arrangements for monitoring the quality of one another's work and preparing and publishing interval estimates of the value of bilateral and multilateral cross-country safety-net support.

If the analytical resources of the world's central banks and largest institutions can be incentivized to attack these estimation problems on a massive scale, the point estimates emerging from different methods should converge over time. Each nation's SAF should also recognize that the confidence intervals that careful statisticians need to place around the different point estimates are apt to narrow with experience, but be sabotaged by regulation-induced innovation and to increase in times of financial turmoil.

Crisis Planning. To make insolvency resolution easier to initiate, supervisors and DFU firms must be made to plan and rehearse for crisis. Richard Herring was the first to propose that managers be required to prepare and file with their principal regulator a standby reorganization plan with which to handle their firm's demise and be obliged to test, update, and refile this plan on a regular basis. This proposal is explored and developed in Herring (2010) and A vgouleas, Goodhart, and Schoenmaker (2010). 
The main value of an up-to-date corporate "living will" or "funeral plan" is as a starting point for planning divestitures that could reduce the flow of subsidies to creditors of declining firms. The existence of such a plan promises to make the threat of putting an insolvent institution into receivership or conservatorship more credible to creditors and counterparties because it promises to lower the costs of executing a takeover. U nlike the chaotic and ineffective haggling observed in addressing the insolvencies of Lehman Brothers and A IG in September 2008 (Ferguson and J ohnson, 2009), having a benchmark winding-up scheme in place would make it much easier for authorities to dilute the claims of zombie stockholders and to negotiate haircuts with uninsured creditors.

Security Design. A nother way of making insolvencies easier to handle would be to reestablish extended liability for some or all classes of financial-institution stock. A n important source of systemic risk is the limited liability that stockholders enjoy. Practically speaking, the less capital stockholders provide, the more safety-net support flows to them and their counterparties. Extended liability means that a supervisor's decision to liquidate an insolvent commercial or investment bank carries with it a right to collect specified amounts of additional funds from the personal or corporate assets of assessable stockholders. Holders of extendedliability stock (i.e., "assessable shares") in a liquidating firm accept the obligation to absorb to a specified degree the first waves of corporate losses that are found to exceed the value of the capital explicitly accumulated at the corporate level. Several now-industrialized countries (including the United Kingdom, the U.S. and Canada) imposed extended liability on bank shares when their safety nets and private contacting environments were less well-developed. 
Extending stockholder liability would increase transparency, strengthen private market discipline, and improve regulatory accountability at the same time. It would do this by encouraging holders of assessable shares to monitor the firm more closely. Informed investors' interest in trading away their extended liability in adverse circumstances would transform movements in the stock price of publicly traded institutions into a clearer and more timely signal of the strength or weakness of unfolding business plans.

To control compensation that risk managers might earn from promoting aggressive risktaking, bonuses and incentive compensation at any firm for which the value of estimated safetynet subsidies appears substantial could be paid exclusively in slow-to-vest assessable stock. Financial markets would imbed the value of the shareholder's contingent obligation into the price of the issuing firm's assessable shares. Like safety-net subsidies, the value of the contingency would be negligible for any institution that was adequately supporting its risk with paid-in corporate capital. However, safety-net managers' contingent claim on stockholder resources would become increasingly valuable whenever a firm began to take poorly supported risks or to slide into financial distress. By increasing the sensitivity of stock prices to changes in earning power and earnings volatility, assessable shares would reveal stockholder doubt about the viability of troubled institutions in advance of their final slide into zombie status.

Trading in extended-liability stock and what we might call "extended-liability derivatives" would improve the quality of counterparty and regulatory supervision because it would encourage insiders to identify institutions that deserve supervisory attention before stockholder-contributed capital at these institutions can evaporate. Contingent private capital resembles government safety-net support in that it is drawn onto an institution's balance sheet 
when and as its level of distress grows. M ark Flannery's proposal for contingent capital certificates (2009) works in a similar way and would work even better for firms that had assessable shares outstanding. This is because market-based, downward price movements in assessable shares promise to act as a more reliable trigger for forcing debt-to-equity conversions than self-interestedly overstated accounting measures of a troubled firm's net worth.

\section{Strictly Governmental Reforms}

In government supervision, incentive conflict is rooted in three circumstances. First, no one is charged with measuring and monitoring safety-net subsides per se. Second, top government officials have horizons much shorter than the taxpayers they formally serve. Third, taxpayers are not an official's only principal and ordinary citizens are poorly positioned to defend their stake in financial regulation.

Under the assumption that private institutions prepare a regulator-certified unwinding plan and estimate the value of the safety-net support they enjoy, it becomes easy to define the missions of micro- and macro-prudential regulators sharply and independently of the particular bureaucratic structure of regulation a country might establish. The first task would be for agencies to test and verify the estimates of the value of safety-net support that would be supplied to them by institutions under their purview. To do this, they would use robust modeling techniques of solvency assessment and on-site and electronic methods of data collection. They would also be expected to communicate to the Safety-N et A ccountability Office the estimates of safety-net subsidies that they and individual institutions they supervise produce. Each microprudential regulator would also prepare consolidated estimates of the aggregate value of safety- 
net benefits at the firms they supervise and report their methods of aggregation and estimates to the SAF for further analysis.

A second task would be to establish, publicize, and rehearse periodically a prepackaged bankruptcy-like scheme for allocating losses incurred in insolvency and crisis management. A uthorities would be free to deviate from their benchmark plan during an actual crisis, but they would be obliged to explain why they are doing so.

A desirable third task would be to discourage elected officials from trying to win special treatment for firms that contribute money to their campaigns. One way to do this would be to oblige regulatory personnel and elected officials to report to the SA F promptly, fully, and separately on interactions with elected officials that occur outside the public eye.

These three reforms would make the jobs and recruitment of top regulators more difficult. For this reason, the US and other countries would be well advised to establish the equival ent of a publicly funded W est Point for financial regulators and welcome cadets from anywhere in the world. Reinforced by appropriate changes in regulators' oaths of office, such an academy would raise the prestige of this form of public service and instill a stronger and broader sense of communal duty in safety-net managers than the current generation of officials has shown during the current crisis. In view of the damage crises can cause, it is unfortunate that regulators are not trained and incentivized as carefully as military, police, firefighting, and nuclear-safety personnel.

In principle, supervisors should be recruited from a population of individuals who are willing to embrace explicitly the fiduciary duties their agency owes to society and be prepared to 
perform these duties selflessly and conscientiously. Ideally, oaths of office could be reworked to include five duties that conscientious supervisors ought to agree that they owe to the community that employs them:

1. A duty of vision: Supervisors should continually adapt their surveillance systems to discover and neutral ize innovative regulatee efforts to disguise their rule breaking;

2. A duty of prompt corrective action: Supervisors should stand ready to propose new rules and to discipline regulatees whenever a problem is observed;

3. A duty of efficient operation: Supervisors should strive to produce their insurance, loss-detection, and loss-resolution services at minimum cost;

4. A duty of conscientious representation: Supervisors should be prepared to put the interests of the community they serve ahead of their own;

5. A duty of accountability: Implicit in the first four duties is an obligation for safety-net managers embrace political accountability by bonding themselves to disclose enough information about their decision making to render themselves answerable for mishandling their responsibilities.

Legislatures around the world could extend loss-control responsibilities beyond national borders by establishing schemes in which private and governmental monitoring organizations would be able to hold one another financially responsible for the quality of their supervisory work. In the US, Congress has proposed imposing product liability on credit-rating organizations and requiring safety-net managers to move trading in over-the-counter derivatives and other securities to clearinghouses or exchanges when and as their volume becomes large enough to pose material safety-net consequences. This duty affects other countries and would be strengthened if national deposit insurers were made to reinsure in private markets the coverages 
they provide to market makers in derivative instruments. This could be done either by writing credit default swaps or by transacting directly in reinsurance markets.

To offset their enhanced accountability, it would be appropriate to raise the salaries of top officials. However, to lengthen the horizons of safety-net managers, the raise should be framed as deferred compensation that would have to be forfeited if a crisis occurred within three or five years of their leaving office. While the incremental loss of income might seem trivial, the impact on a regulator's reputation and ability to resist lobbying pressure could be considerable. If payouts were tied to measures of safety-net subsidies, deferred compensation would have the further benefit of making incoming appointees more cognizant of unresolved problems that his or her predecessor might be leaving behind.

\section{Summary Implications}

In good times, systemic risk and safety-net subsidies are easy to overlook. Systemic risk is rooted in the economic and political difficulties of monitoring and controlling the production and distribution of safety-net subsidies. Regulation-induced innovation by financial firms is designed to outstrip the monitoring technology and to circumvent the tools and administrative focus that supervisory personnel use in controlling institutional risk-taking.

To reduce the threat of future crises, the pressing task is not to rework bureaucratic patterns of financial regulation, but to repair defects in the information flow and incentive structure under which private and government supervisors manage the safety net. 
Without appropriate reforms in incentives, redesigning capital requirements, introducing a few new regulatory instruments, and relocating bureaucratic responsibilities for particular components of national safety nets will change the form, but not the substance of safety-net arbitrage. To build a robust and reliable system of financial regulation, financial-institution managers and national regulators must accept responsibility for estimating and controlling in a timely, proactive, and accountable manner the safety-net consequences of transformative financial contracts and institutional structures. 


\section{REFERENCES}

A charya, V iral, Phillipp Schnabl, and Gustavo Suarez, 2010. "Securitization W ithout Risk Transfer." NBER W orking Paper N 0. 15730. Cambridge, M A (February)

A vagouleas, Emilios, Charles Goodhart, and Dirk Schoenmaker, 2010. "Living Wills as a Catalyst for A ction." (http://ssrn.com/abstract:1533808).

Baker, Dean, and Travis M cA rthur, 2009. "The V alue of the "Too Big to Fail" Big Bank Subsidy." Washington, DC: Center for Economic and Policy Research Issue Brief (September).

Carbo-V alverde, Santiago, Edward K ane, and Francisco Rodriguez-Fernandez, 2009. "Evidence of Regulatory A rbitrage in Cross-B order M ergers of B anks in the EU." N ational Bureau of Economic Research W orking Paper N o. 15447.

Duan, J-C, A . F. M oreau, and C. W. Seal ey. (1992). "Fixed-Rate Deposit Insurance and RiskShifting B ehavior at Commercial Banks," J ournal of B anking and Finance, 16, 715-42.

Eberlein, Ernst, and Dilip M adan, 2010. "Unlimited Liabilities, Reserve Capital Requirements, and the Taxpayer Put Option," U npublished W orking Paper. College Park, M D: University of M aryland ( $M$ arch 20).

Flannery, M ark J., 2009. "Stabilizing Large Financial Institutions with Contingent Capital Certificates." U npublished University of Florida W orking Paper (September 18).

Ferguson, Thomas, and Robert J ohnson, 2009. "Too Big to Bail: The "Paulson Put," Presidential Politics, and the Global Financial M eltdown," International J ournal of Political Economy, 38, no. 1 (3-34) and no. 2 (5-43).

Gorton, Gary, 2008. "The Panic of 2007." U npublished W orking Paper. N ew Haven: Y ale University.

Gropp, Reint, and Gerard M oerman, 2003. "M easurement of Contagion in B anks' Equity Prices." Frankfurt: European Central B ank W orking Paper N 0.297 (December).

Hart, Oliver, and Luigi Zingales, 2009. "A N ew Capital Regulation for Large Financial Institutions," Chicago B ooth Research Paper N 0. 09-36 (October 2).

Herring, Richard J ., 2010. "W ind-down Plans as an A Iternative to B ailouts: The Cross-B order Challenges," in K enneth Scott, George Shultz, and J ohn Taylor (ed.), Ending Government B ailouts as We K now Them, Stanford U niversity: Hoover Press, 2010 
Hovakimian, A rmen, and Edward J. K ane. (2000). "Effectiveness of Capital Regulation at U.S. Commercial Banks, 1985-1994," J ournal of Finance,55(M arch).451-469.

Huang, Xin, Hao Zhou, and Haibin Zhu, 2009. "A Framework for A ssessing the Systemic Risk of M ajor Financial Institutions." W orking Paper, University of Oklahoma (M ay).

K ane, Edward J., 1986. "A ppearance and Reality in Deposit Insurance: The Case for R eform," J ournal of Banking and Finance, 10 (J une), 175-188. Institute Press.

1989. The S\&L Insurance M ess: How Did It Happen? W ashington: U rban

2009a. "Incentive Roots of the Securitization Crisis and Its Early

M ismanagement," Y ale J ournal of Regulation, 21 (W inter), 28-33.

2009b. "Extracting Nontransparent Subsidies by Strategically Expanding and Contracting a Financial Institution's B alance Sheet," L ournal of Financial Services Research, 35 (December), 161-68.

2010. "The Importance of M onitoring and M itigating the Safety-N et Consequences of Regulation-Induced Innovation," Review of Social Economy (forthcoming).

K upiec, Paul, 2009. "How W ell Does the V asicek Basel M odel Fit the Data?: Evidence from a Long Time Series of Corporate Credit Rating Data." W ashington: Federal Deposit Insurance Corporation (N ovember).

Levine, Ross, 2009. "The Sentinel: A n A uxiliary Precaution for Governing Financial Regulations." Presented at Federal Reserve Bank of Chicago's Twelfth A nnual International Conference (September).

Lo, A ndrew W., 2009. "The Feasibility of Systemic Risk M easurement," Testimony B efore the Financial Services Committee of the U.S. House of Representatives (October 19).

M erton, R obert C. (1977). "A n A nalytic Derivation of the Cost of Deposit Insurance and L oan Guarantees," Journal of Banking and Finance, 1, 3-11.

(1978). "on the Cost of Deposit Insurance W hen There A re Surveillance Costs," J ournal of Business, 51, 439-52.

Ronn, Ehud, and A.R. V erma. (1986). "Pricing Risk-A djusted Deposit Insurance: A n OptionBased M odel," J ournal of Finance, 41, 871-95. 


\section{TABLE 1}

\section{LAYERS OF INCENTIVE CONFLICT THAT ENCOURAGE WEAK ENFORCEMENT}

1. A symmetric Information (Creates Easy A libis and Opportunities for Coverup)

2. Uncertain hold on positions (Shortens horizons)

3. Reputational and Budgetary Damage Generated by Industry Criticism (Dysfunctional Accountability)

4. Role of Political Screening and Post-government Career Opportunities in Recruitment (Revolving Door)

5. Attraction of Passively W aiting for a Cyclical Upswing (Gambling for Resurrection)

6. Budgetary Cost of Training Staff and A dministrative Difficulties of Winding Down Complex Firms

7. A dverse Effects of Prudential Restraints on M acroeconomic Growth

- A Complete Program of R eform Should M itigate These Difficulties by Improving Public and Private Compensation Structures, Performance M easurement, and Reporting Responsibilities. 